\title{
Out of the closet and into \\ the museum: \\ The costumes of \\ Mika Haka
}

The Auckland Museum recently acquired a significant collection of costume and related material from New Zealand entertainer and community leader Mika Haka. Mika has collected material for over thirty years and it was always his intention that his material would become part of a museum collection. Mika's motivations to offer material to the Auckland Museum included the positive experiences he had with the Museum and that these objects would speak for takatāpui / LGBT+ communities who are underrepresented in museum collections. The process of selecting material for the museum was a challenge due to the size and variety of the collection. The costumes that represent Mika's

life and are now preserved in the Auckland Museum have wide ranging research and display potential and show the importance of museums collecting contemporary material.

Keywords: \#Museum \#Collecting \#Takatāpui / LGBT+ \#Costume \#Performance history \#Māori 
Mika Haka is a New Zealand entertainer and community leader who has been at the forefront (or arguably fringe) of New Zealand popular culture since the 1980s. Mika's varied accomplishments include dancer, singer, actor, model, producer, director, hairdresser, aerobics instructor, activist, entrepreneur and youth advocate. On his business card he describes his role as 'Creative' which is perhaps the most fitting description. Through his charity work he actively supports and empowers young adults particularly LGBT+ youth. Mika identifies as takatāpui. This is a traditional Māori word that has been reclaimed to describe all Māori people who identify with diverse sexualities, sexes and genders.

Mika's entertainment career grew in the 1980s, including a regular role in the New Zealand television drama Shark in the Park in which he played a police officer. His 'big break' occurred in 1991 with the release of a remake of the song / Have Loved Me a Man produced by Dalvanius Prime. Mika's version, which he describes as New Zealand's 'first gay pop hit', was not played by many radio stations due to its overt gay message. Mika's celebrity status and notoriety increased in the 1990s with several high-profile appearances. These included staging a haka featuring more than 300 performers at Hero (a gay dance party), playing a takatāpui man in the Academy Award winning film The Piano, appearing naked as a model in artist Christine Webster's photography exhibition Black Carnival and performing at the Edinburgh Festival.

In 2008 Mika founded the Mika Haka Foundation, a charitable organization that remains his major focus. Establishing a foundation that supports, mentors and provides opportunities for young adults (many of whom could be described as at-risk) demonstrates Mika's commitment to community and young adults. His first charitable trust Torotoro, established in 2001, promoted healthy life choices to young adults, an issue he feels strongly about. 'There was no junk food at all, no alcohol at all, no cigarettes, and don't even start on anything else. But there were condoms if they were having sex'.

Mika's professional and personal life has been preserved in the Auckland Museum where he deposited a substantial collection of costumes and related material. In making this donation Mika fulfilled a long-term goal of preserving his life through material culture. This article discusses Mika's motivations to contribute material to a museum and the process of selecting which material was acquired for the collection.

\section{THE COLLECTION}

Mika made a conscious decision early in his career to preserve material representing his life. ' $(\mathrm{He})$ decided early on that his life was worth memorializing. Over three decades ago he set himself to the task of preserving his history in photographs, artefacts and narratives'. This desire was not for personal sentimental reasons and neither was it for practical reasons as his costume styling changed constantly through his career. Mika kept material from his career including costumes, props, posters, correspondence and set designs with the intention they would become part of a museum collection.

Mika has previously donated material to other public institutions. In 2011 he donated material to Te Papa Tongarewa / Museum of New Zealand, and he had earlier donated material to LAGANZ (The Lesbian and Gay Archive of New Zealand) at the Alexander Turnbull Library. The author began visiting Mika and assessing his collection in 2016 with the goal of finding material for Tämaki Herenga Waka: Stories of Auckland a new, long-term exhibition scheduled to open at the Auckland Museum in late 2020 .

Mika estimates he had approximately 1,200 costumes in his collection. The majority worn by him or members of his performance groups dating back to the 1990s. Many of the costumes were unwieldy and decorated with a variety of non-textile elements including sequins, feathers, Christmas lights and animal parts. Mika's costumes fill his large suburban Auckland studio and two shipping containers. In addition to costume he had large collections of photographs and ephemera from his performances including posters, leaflets and sound recordings.

Another large collection was Mika's Māori 'kitsch' material that he had amassed over many years. Mika puts his interest in this material down to his childhood when he was adopted by a non-Māori family. Without ready access to Māori culture Mika would utilize the Māori material culture he saw around him, including tourist depictions of Māori people, to form his identity.

The storage of his material was systematic and each box or containe was labelled with its contents. (Fig. 1) During the acquisition process Mika would often explain the reason for this level of organization was that he was 'a natural archivist'.

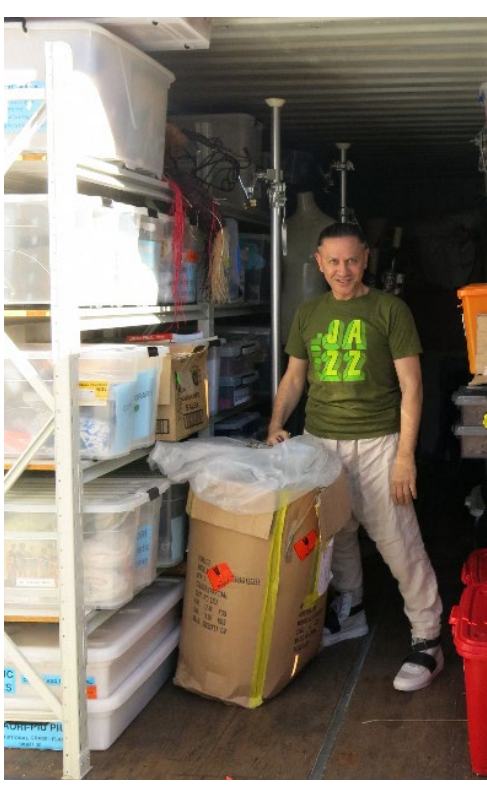

Figure 1. 
In addition to keeping material from his long career Mika is unusual in that he has maintained exceptionally detailed records on his collection both in the form of written documentation and his own personal recollections. From the perspective of a museum curator this level of record keeping is both unusual and highly valuable. Museum exhibitions rely on the ability to communicate to an audience an engaging story through objects. Ideally objects should not only illustrate a story but provide some unique insight or emotional response that written text or oral history cannot. In contemporary museum exhibitions it is not enough to display an artefact simply because it was worn or owned by an individual, be they a celebrity or not. In preserving the narrative associated with his costumes and freely sharing his own anecdotes Mika has ensured his collection has high display potential in the future.

Clothing was an obvious form of object to represent Mika in a museum collection as his outlandish, provocative styling has always been a major part of his celebrity and persona. 'Clothes are my thing. I'm from a generation where you didn't get into places if you were Māori and you weren't well dressed'. Mika's costumes relate to his career as a performer and his takatāpui identity incorporating high fashion, burlesque, cabaret, camp and aspects of 'traditional' Māori culture. He describes his style as 'not drag, but not male'.

\section{MOTIVATIONS TO OFFER MATERIAL TO THE MUSEUM}

People gift or sell material to a museum for a variety of reasons.

Historically it was a measure of personal prestige, wealth and good taste to donate material to a museum. Today donors are often motivated by a sense of responsibility to preserve the past and a need to divest that responsibility. Museums are seen as validators of history. Therefore, in assuring his life story is part of a museum, Mika is validating not only his identity but that of takatāpui / LGBT+ people and Māori people who had an urban upbringing - both are groups underrepresented in museum collections. This philosophy of considering the needs of community is consistent with Mika's approach to life and his work.

Memorable museum visits and positive experiences with staff members may also inspire people to donate items. In this way acquisitions become part of a reciprocal relationship and a way for individuals to mark their positive experiences at the museum. Mika first worked with the Auckland Museum on a project in 2009, a series of spoken word performances titled Wonderland: The Mystery of the Orchid.
This was a positive experience for Mika and encouraged him to consider the Auckland Museum as a future home for his collection.

It is unusual for an artist to donate material while they are still working. An additional motivation for Mika to part with a substantial portion of his collection was the publication in 2018 of his biography I Have Loved Me a Man: The Life and Times of Mika Haka written by Sharon Mazer. Mika felt that once his life story had been recorded he was able to let go of the material that represented it. With the publication of his biography Mika was ready to move on to his next project. Mika was pragmatic in his approach to letting go of his collection. If anything, the acquisition process was too slow for him. Mika's lack of sentimentality was a different experience for the curator, who was more accustomed to donors acting more emotionally, but it made the project more efficient. Mika was clear on the material he was ready to let go, the material he still required and which pieces he would expect payment for rather than donate. This is another example of his systematic approach to his collection. Mika had considered the divestment and deaccession of his collection which is another role of the curator or archivist.

SELECTION OF MATERIAL

One of the challenges of selecting material for the museum collection was the sheer size of Mika's collection. The first visits to the studio were overwhelming for the curator as Mika brought out so many costumes. He was able to narrate the history of each costume in detail. This often included the multiple performances they had been worn in, details on the designer and other anecdotes that were or were not always related to the costume.

Initially the curator and donor did not assign significance to the costumes in the same way. Significance for the donor was often related to who designed the outfit, which other celebrities had worn clothes by the designer and the price of the outfit. These measures of significance were circumstantial for the curator who was focused on the historic relevance of the outfits and how they could potentially be utilized in upcoming exhibitions. This was a lesson for the curator in prepping the donor as to how museums assign significance and an example of the need to build a strong relationship with the donor which can only develop over time. After discussing significance from a curatoria perspective Mika quickly realized which costumes would be most relevant for the museum and the selection process was streamlined. 
The timespan between the first visit to Mika's studio and the final selection of objects was three years. This gave the donor and curator time to build a strong relationship and allowed the curator to learn more about the career and motivations of the donor.

The acquisition of new material for the museum is an important role of the curator. Curators are guided by a collecting policy and need to justify the significance, research and display potential of objects before acquiring new material. The Auckland Museum Collection Policy for 2018 / 2019 makes specific references to strengthening the collection in contemporary Māori fashion, material that represents contemporary Māori art practice and objects that show Māori participation in New Zealand life in the $20^{\text {th }}$ and $21^{\text {st }}$ Centuries. The Mika Haka Collection ticks all these boxes. Collecting priorities have evolved and continue to evolve in museums, making contemporary material such as the Mika Haka Collection more relevant to the purpose of the museum.

An issue with contemporary objects is that many are inherently ephemeral and not produced to last for generations. A rubber suit Mika had worn on many occasions and which would have been aesthetically appealing was not collected due to the inherent issues with the material. The unstable nature of rubber meant the outfit would only be able to be on display for a maximum of six months. Storage would also be problematic as it would require a specific temperature and humiditycontrolled environment beyond the already strict museum environment.

Museums need to be responsible for ensuring they can provide a safe home to an object for its entire lifespan.

In total 12 costumes were selected for the Auckland Museum Collection. Four of these costumes are described here and their significance discussed.

"SUGGESTIVE" COSTUME WORN ON WHEEL OF FORTUNE This costume (Fig. 2) made by DeeZaStar was worn by Mika from 19911995. The costume is representative of Mika's early career when he did not have the financial resources for elaborate, designer costumes and was instead using shock value in his costuming. 'Mika's performances (in the early 1990s) were becoming more extreme, often in direct response to attempts to force him back - if not into the closet, then certainly into line'.

The most significant occasion Mika wore this outfit was in 1993 on an episode of the New Zealand version of the television game show Celebrity Wheel of Fortune. During the episode Mika performed

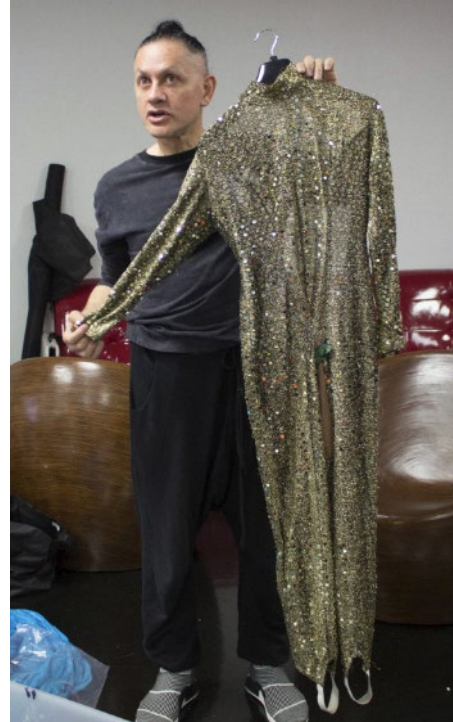

Figure 2.

his version of the song / Have Loved Me a Man which resulted in a complaint to the Broadcasting Standards Authority, an authority established to ensure content on television is not offensive to society. The complainant believed Mika's appearance on a family show breached good taste and decency referencing the suggestive answers he gave to questions, his 'gyrations', suggestive body movements and the 'distasteful' song he sang. 'Such performances surely should be restricted to adult clubs - certainly not on a TV family type show'. The episode screened on Easter Sunday which caused further offence to the complainant.

In the written response to the complaint the state broadcaster TVNZ emphasised Mika's performance was comedic rather than sexualised, pointing to 'the tradition of female impersonators as entertainers (including) Danny La Rue, Barry Humphries and pantomime dames'. TVNZ also expressed the belief that Mika's appearance was neither offensive nor unsuitable for children suggesting, 'any sexual innuendo in Mika's performance would have gone over the heads of the prepubescent'. The Broadcasting Standards Authority did not uphold the complaint considering the 'enthusiastic reaction from the audience which included a lot of children' in making their decision. However, the Authority made the point in its findings that 'broadcasters must exercise some degree of caution when broadcasting an item in which a female impersonator has a significant role'. 
The primary historic significance of this costume is its ability to speak to the societal change and increased tolerance toward LGBT+ and gender fluid communities in New Zealand. However, terms such as 'female impersonator' would no longer be appropriate (or accurate) to describe Mika. His costume and performance would be considered tame to today's audience and unlikely to cause offence. In the period since this complaint in 1993, LGBT+ and gender fluid people have become more visible both in society and in television and other media. This costume would have high display value and could be used by the museum in a discussion on a wide range of subjects including gender, sexuality, television history and censorship.

Another elaborate costume was also made by DeeZaStar, a long time Mika collaborator. It is made from 'faux Issey Miyake fabric scraps left over from the 2006 Commonwealth Games' and features a beaded tiki. As with many of his costumes Mika has his own name for this outfit which is his 'Issey Miyake meets Grace Jones octopus dress'.

The most significant occasion Mika wore this outfit was for a performance after the death of Dame Te Atairangikaahu (the Māori Queen) in 2006. Mika first performed for Te Atairangikaahu in 1986 when he was with the Māori theatre group Te Ohu Whakaari. She enjoyed watching him perform and over the years the two formed a bond. Mika recalls Te Atairangikaahu would describe him as the 'official naughty Māori' or the 'Māori Court Jester'. Inherent in these descriptions is the suggestion Mika is something of a 'loveable rogue', a provocateur, but one who only has the best intentions.

Mika actively uses his performances and celebrity to challenge racism and homophobia which at times has made him unpopular with more conservative Māori performers. Mika has spoken out about the homophobia that exists in Māori society noting that many Māori people will speak out on land rights or human rights but treat takatāpui / LGBT+ people as invisible. In 2006 Mika responded to an anti-gay demonstration organized by a Māori fundamentalist Christian church leader by standing in front of protestors holding a single flower. Mika's close relationships with many influential Māori leaders such as Dame Te Atairangikaahu shows that while institutionalized homophobia is present in Māori society, it is not universal. Mika has described his invitation to perform after the death of Te Atairangikaahu as validation of his place as a Māori performer.

This costume could be used to speak to the tension between LGBT+ and Māori identities, Mika's role as a 'naughty Māori' and his close relationship to Dame Te Atairangikaahu.
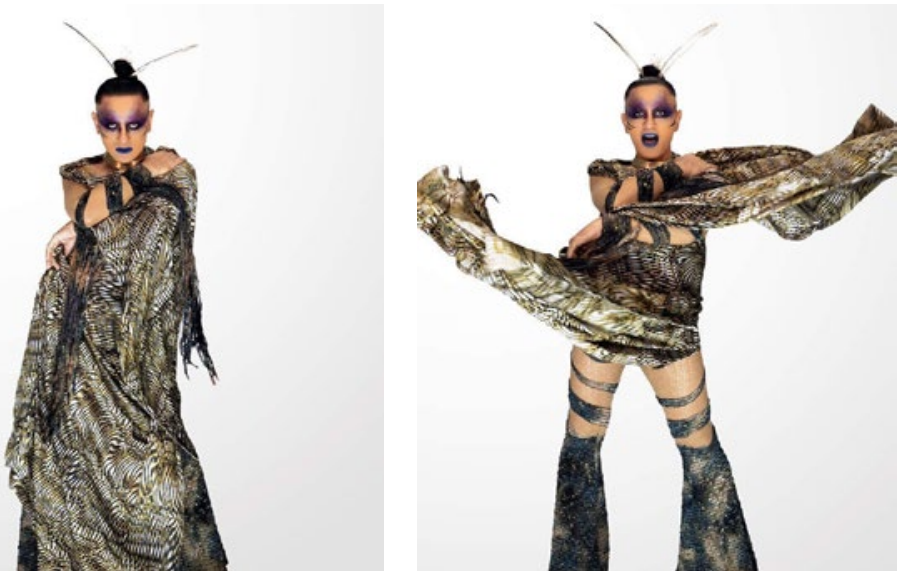

Figure 3

THE OUTFIT THAT CAUSED A 'COMMUNIST SCARE'

This outfit (Fig. 3) was designed for Mika by Patrick Steele, an Auckland based designer active between the 1970s and 2000s. The outfit is made from lycra and is designed to appear as though large portions of the body appear naked.

Mika wore this costume on several occasions including the final Hero Parade and the Sydney Mardi Gras. The most memorable occasion for Mika was when he wore it while on tour in Cuba in 2008. According to Mika this costume caused a 'communist scare'. Mika recounts that Cuban Government officials spoke to him with concerns his performance would be immoral and questioned whether he intended to perform naked. Homosexuality was illegal in Cuba until 1979 and the country has government enforced censorship. Mika responded to the Government officials that he would be wearing a traditional Māori costume referring to this outfit. This response from Mika is an example of his quick wit but also his opinion that what many people perceive as traditional Māori performance is post-colonial. 'People ask if my costume is traditional Māori. I say yes. Why not? The piupiu was made up by the white man as well'.

Mika believes a Māori cultural show does not have to fit into a stereotype and his assertion that this skin-tight, semi-naked outfit is traditionally Māori is valid in his opinion. This brings up an interesting and relevant discussion as to what constitutes a Māori textile. Is it an item made by a Māori person, worn by a Māori person or is it the design or material the textile is made from that designates it Māori? This costume could be displayed to challenge the stereotype of Māori performance and discuss notions of authenticity. 


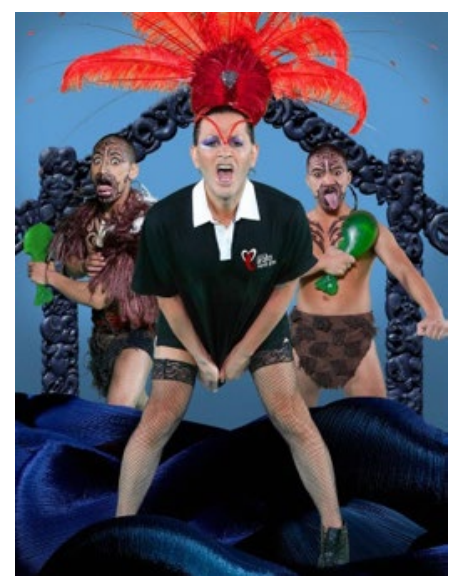

Figure 4.

BLACK RUGBY JERSEY AND RED BURLESOUE HEADDRESS This ensemble (Fig. 4) is a black rugby jersey and a red burlesque style headdress designed by contemporary fashion designer Kiri Nathan. Mika accessorized this outfit with black fishnet stockings and stilettos. The ensemble was worn by Mika during the 2011 Rugby World Cup in Auckland. As part of the entertainment surrounding the World Cup Mika organized the Aroha Mardi Gras, a music and dance event that featured drag, burlesque and multicultural performances.

The juxtaposition of the black rugby jersey with the burlesque headdress and fishnet stockings is not just comedy or for shock value. The costume can also be seen as a comment on gender identity and the important role elite male athletes have as role models in New Zealand. The national rugby team the All Blacks and therefore the black rugby jersey are arguably the most quintessential symbols of masculinity in New Zealand. Rugby players are role models for many people especially Māori and Pacific youth. In 2018 Mika made headlines by claiming his former mentor Carmen (a drag performer, brothel owner and activist who was a household name in New Zealand) had several All Black lovers.

Through his charity Mika works extensively with LGBT+ I takatāpui youth. Common feelings for LGBT+ youth are isolation, fear, guilt, depression and hopelessness. LGBT+ / takatāpui youth are overrepresented in negative statistics for mental health, addiction and suicide. Mika has stated publicly that an openly gay All Black would have a positive impact on those struggling with their sexuality and hopes one day a male rugby star will have the courage to come out. 'I think the All Blacks are positioned enough to support that person'. Mika's appearance in a black rugby jersey speaks to his desire for LGBT+ takatāpui youth to seek positive role models and develop a positive attitude toward their body image.

This outfit could be used in an exhibition to discuss sporting culture, masculinity, youth culture, sexuality or multiculturalism.

\section{CONCLUSION}

Tāmaki Herenga Waka: Stories of Auckland, a long-term exhibition that tells the story of the people and places of the city of Auckland, will open at the Auckland Museum in late 2020. Mika Haka will feature in a section of the exhibition titled Creators and Innovators. This section of the exhibition explores the stories of 'Aucklanders who have thought outside the box to solve a problem or seen an opportunity and acted on it'. The costume that represents Mika will be the Patrick Steele designed flesh toned body suit, the costume that Mika describes as 'the outfit that caused a communist scare'. This costume was chosen to be displayed for several reasons. Aesthetically it would be appealing and evoke curiosity in a visitor, it was a costume Mika wore in many high-profile performances and it challenges the perceived 'traditional' Māori identity that is archetypally depicted in museums.

The Mika Haka Collection will provide much needed breadth to the Māori collection at the Auckland Museum and shows the importance of collecting contemporary material. The Mika Haka Collection acknowledges takatāpui and urban Māori as equally valid Māori identities and questions the authenticity of some 'traditional' Māori material in museums. Museum collecting priorities continue to evolve ensuring museums give voice to those previously unrepresented in museums.

The acquisition of Mika Haka's costumes for the Auckland Museum collection will allow the museum to display and discuss several aspects of popular culture. These include performance, television, gender, sexuality, contemporary Māori identity, fashion, activism and youth culture. Mika Haka's mission to preserve his personal collection of material culture and see it in a museum collection has been achieved. He can add 'museum donor' to his list of many accomplishments. 


\section{REFERENCES}

Broadcasting Standards Authority. "Decision No: 81/93 in the matter of the Broadcasting

Act 1989 and a complaint by Laurie Collier of Upper Hutt." https://www.bsa.govt.

nz/oldsite/assets/PDF-Decisions/1993/81

9301071993Laurie-Collier.pdf [accessed

December 30, 2019].

Kerekere, Elizabeth. Growing up takatāpui: Whānau journeys. Auckland, New Zealand Tiwhanawhana Trust and RainbowYOUTH 2017.

Māori Television. "Gay Icon Carmen Had All Black Lovers." Te Ao Māori News, October 2, 2018. https://teaomaori.news/gay-icon-

carmen-had-all-black-lovers-says-mika

[accessed December 30, 2019].
Mazer, Sharon. I Have Loved Me a Man: The Life and Times of Mika Haka. Auckland, New Zealand: Auckland University Press, 2018.

Szczepanski, Joanna. “Understanding donor motivations". Museum Management and Curatorship 32, no. 3 (2017): 272-280.

van Beynen, Jack. "Mika Haka: the Court Jester of Maoridom." Stuff, September 15, 2016. https://www.stuff.co.nz/entertainment/ arts/84206824/mika-haka-the-court-jester-ofmaoridom [accessed December 30, 2019]. 